\title{
Treatment Effects of Choline Chloride-based Deep Eutectic Solvent on the Chemical Composition of Red Pine (Pinus densiflora)
}

Gu-Joong Kwon, ${ }^{\mathrm{a}, \mathrm{b}}$ Bong-Suk Yang, ${ }^{\mathrm{c}}$ Chan-Woo Park, ${ }^{\mathrm{d}}$ Rajkumar Bandi, ${ }^{\mathrm{b}}$ Eun-Ah Lee, ${ }^{\mathrm{d}}$ Ji-Soo Park, ${ }^{\mathrm{d}}$ Song-Yi Han, ${ }^{\mathrm{b}}$ Nam-Hun Kim, ${ }^{\mathrm{b}, \mathrm{d}}$ and Seung-Hwan Lee ${ }^{\mathrm{b}, \mathrm{d}, *}$

Effects of deep eutectic solvent (DES) treatment were determined for the chemical composition of the sapwood and heartwood of red pine (Pinus densiflora). Two DES systems were made from the mixture of choline chloride $(\mathrm{ChCl})$ and two different hydrogen bond donors (HBDs), namely, lactic acid (LA) and glycerin (GLY), with different molar ratios (1:2, 1:6, and 1:10). The yield of the solid residue after DES treatment decreased with an increase in the HBD concentration and treatment time, indicating that the water-soluble fraction was increased. The amount of solid residue was lower in the DES with LA than in DES with GLY, and higher in sapwood than in heartwood during both DES treatments. There was no substantial change in the lignin content of the samples, each being 24.7 to $29.5 \mathrm{wt} . \%$, based on the mass of the treated product. Similar to the yield of the solid residue, cellulose and hemicellulose content in the treated product decreased with an increase in the HBD concentration and treatment time, and it was higher in sapwood than in heartwood. The cellulose crystallinity exhibited a slight increase with increasing treatment time, but there was no difference among the treatments using different molar ratios and between sapwood and heartwood.

Keywords: Deep eutectic solvent; Red pine; Choline chloride; Lactic acid; Glycerin; Chemical composition

Contact information: a: Kangwon Institute of Inclusive Technology, Kangwon National University, Chuncheon-Si, 23341, Republic of Korea; b: Institute of Forest Science, Kangwon National University, Chuncheon-Si, 24341, Republic of Korea; c: College of Life Science and Biotechnology, Dongguk University, Goyang-Si, 10326, Republic of Korea; d: Department of Forest Biomaterials Engineering, College of Forest and Environmental Sciences, Kangwon National University, Chuncheon-Si, 24341, Republic of Korea;

* Corresponding author: lshyhk@kangwon.ac.kr

\section{INTRODUCTION}

In recent years, discovering renewable feedstock to produce fine chemicals, materials, and fuels has become important due to increasing energy demands and environmental issues (Hou et al. 2017a; Ho et al. 2019). Lignocellulosic biomass is the most abundant, low-cost, and renewable biomass that can be utilized for conversion into a valuable chemical or materials (Isikgor and Becer 2015; Capolupo and Faraco 2016; Ahorsu et al. 2018; Lee et al. 2019). The biorefinery conversion of lignocellulosic materials is a developing process for efficient and economically viable utilization as a pretreatment to obtain high-value products. Solvents for the separation and extraction of lignocellulosic materials include organic solvents (Espinoza-Acosta et al. 2014; Zhang et al. 2016). However, many organic solvents have adverse effects on the environment and the human body (Agbor et al. 2011; Kucharska et al. 2018).

An ionic liquid refers to a substance that exists in a liquid state at room temperature

Kwon et al. (2020). "Choline chloride eutectic solvent," BioResources 15(3), 6457-6470.

6457 
and forms ionic bonds. The ionic liquids are considered as being environmentally friendly or green solvents because they have favorable properties, including high solvent capacity towards both organic and inorganic materials and negligible vapor pressure, which reduces the volatile organic compound emission (Zhao 2003; Sirviö et al. 2016). Furthermore, it is possible to appropriately select cations and anions according to need, as well as control their characteristics (Sun et al. 2009; Espinoza-Acosta et al. 2014; Han et al. 2017; Merza et al. 2018). The pretreatment of woody biomass by an ionic liquid increases the accessibility of enzymes during saccharification by reducing the degree of crystallization of cellulose and selectively separating the constituents (Sathitsuksanoh et al. 2012; George et al. 2015; Han et al. 2020).

However, the manufacturing of ionic liquids is cumbersome. They are very expensive; some ionic liquids are harmful to the human body and can also cause environmental hazards. Deep eutectic solvents (DESs) have been developed as new alternative solvents to resolve these problems (Shamsuri and Abdullah 2010; Dai et al. 2013). DESs are of increasing interest in science and industry because they are simple to use, safe, cost-effective, and do not present problems in purification or disposal (Yadav et al. 2014). These solvents are generally environmentally friendly, biocompatible compounds that are composed of a hydrogen bond acceptor (HBA) such as quaternary ammonium salts and a hydrogen bond donor (HBD) such as amides, carboxylic acids, and alcohols. When released, they are not environmentally hazardous. Their synthesis is economically feasible and allows the incorporation of the components of green chemistry (Malaeke et al. 2018). Typically, deep eutectic solvents consist of large, non-symmetric ions that have low lattice energy and hence, low melting points. They are usually prepared by mixing an HBA and HBD at moderate temperatures to form eutectic mixtures. Hydrogen bonding results in charge delocalization or self-association occurring between the HBA and HBD, and consequently the melting point of the eutectic mixture is much lower as compared to the individual compounds (Satlewal et al. 2018). The $\mathrm{H}$ bonding is the key for DESs forming. The $\mathrm{H}$ bonding is very unique compared with other bonding types. $\mathrm{H}$ bonding can have different bonding forces and lengths depending on the ambient conditions for the same component (Kadhom et al. 2017). Choline chloride is the most commonly used HBA because it is low cost, biodegradable, safe, non-toxic, and extractable from biomass. And, DESs mixtures formed on the basis of choline chloride tend to be controlled by the stability of carboxylic acids, amides, or alcohol.

In view this, previous studies for DESs have been focused on the physicochemical characterization, fractionation efficiency, pre-treatment for nanofibrillation, extraction bioactive substances, and delignification at constant molar ratios, temperature and time conditions using DES formed by combining with various HBDs (Sirviö et al. 2015; Hiltunen et al. 2016; Loow et al. 2018; Ong et al. 2019; Sakti et al. 2019; Smink et al. 2019; Yu et al. 2019). However, the effect of DES pH was not taken into consideration in most of these reports. On the basis of $\mathrm{pH}$, Skulcova et al. (2018) classified DESs into two groups, i.e. organic acid as HBD (pH 0 to 3.0), and polyol as HBD (pH 4.0 to 4.5), and they emphasized the importance of efficient DES application and suggested that the DES $\mathrm{pH}$ value can greatly affect the chemical reaction with the components of biomass. In this context, in order to take DES $\mathrm{pH}$ into account, two representative HBDs, i.e. lactic acid (LA) for organic acid and glycerol (GLY) for polyol were selected. The main aim of this study was to investigate the effect of DES treatment time and mole ratio of HBDs with different $\mathrm{pH}$ values on the chemical composition of sapwood and heartwood of the red pine.

Kwon et al. (2020). "Choline chloride eutectic solvent," BioResources 15(3), 6457-6470.

6458 


\section{EXPERIMENTAL}

\section{Materials}

The red pine was provided by the Research Forest of Kangwon National University in Korea. The sapwood and heartwood were separated by identifying the color difference in the cross-sectional disk. The percentage of sapwood and heartwood was $80.5 \%$ and $19.5 \%$, respectively. Each sample was cutter-milled to a specific size (40- to 80-mesh). The milled red pine was extracted with acetone before DES treatment. Choline chloride $(\mathrm{ChCl})$, LA, and GLY were purchased from Daejung Chemical Co., Ltd., Siheung, Korea. All other reagents were of analytical grade and used without further purification.

\section{Methods}

\section{DES treatment}

Two DES systems were prepared using the heating method by mixing $\mathrm{ChCl}$ and two hydrogen bond donors, i.e., LA and GLY, with molar ratios of 1:2, 1:6 and 1:10, respectively. The two components of each mixture were placed in a round-bottom flask with magnetic stirring for $10 \mathrm{~min}$ at $100{ }^{\circ} \mathrm{C}$ until a clear colorless liquid was obtained. Wood powder ( $1 \mathrm{~g}$, oven-dry) was added to the DESs $(20 \mathrm{~g})$ and heated at $100{ }^{\circ} \mathrm{C}$. The ratio of the sample and the DESs was 1:20 (w/w). The treatment times were $2 \mathrm{~h}, 4 \mathrm{~h}, 6 \mathrm{~h}$, and $12 \mathrm{~h}$. After the treatment, the sample was filtered. The solid residue was washed using distilled water/acetone $(1: 1)$ two times, washed with water, and dried at $105^{\circ} \mathrm{C}$ to obtain the DES treatment sample.

\section{Chemical composition measurement}

The chemical composition of the sample was determined using a scaled-down version of the Klason protocol of TAPPI T222 om-88 (2011). Briefly, $0.2 \mathrm{~g}$ of sample was prepared at room temperature with $3 \mathrm{~mL}$ of $72 \% \mathrm{H}_{2} \mathrm{SO}_{4}$ for $2 \mathrm{~h}$. The reaction was diluted using $112 \mathrm{~mL}$ of deionized water. The solution was autoclaved at $121^{\circ} \mathrm{C}$ for $1 \mathrm{~h}$. The solid was filtered through a $1 \mathrm{G} 4$ glass filter and dried overnight at $105{ }^{\circ} \mathrm{C}$. The acid-insoluble lignin content was determined by the ratio between the weights of the solid residue and the initial amount of the sample. The acid soluble lignin was determined using a UV-vis spectrophotometer (Lamda 35, PerkinElmer, Waltham, MA, USA) at a wavelength of 205 nm.

The sugar analysis of samples was performed using Bio-LC (ICS-3000, Dionex, Sunnyvale, CA, USA) according to the NREL analytical procedure (Sluiter et al. 2008). High-performance anion-exchange chromatography (HPAEC) was connected with electrochemical detection using pulsed amperometry (gold electrode), which was used for quantitation of neutral sugar. The sample was chromatographed on a CarboPac PA-1 column. The system was operated in isocratic mode at a flow rate of $1.0 \mathrm{~mL} / \mathrm{min}$ with a mixture of $250 \mathrm{mM}$ of sodium hydroxide $(20 \%)$ and deionized water $(80 \%)$. Five types of sugars (glucose, xylose, arabinose, galactose, and mannose) were calculated using Chromeleon software (Version 6.8, Dionex).

\section{Characterization techniques}

The X-ray diffraction patterns of the DES treatment sample were recorded with an X-ray diffractometer (DMAX 2100V, Rigaku, Akishima, Japan) operated at $40 \mathrm{kV}$ and 30 $\mathrm{mA}$. Scattered radiation was detected in the range of $2 \theta=10$ to $35^{\circ}$ at a scan rate of $1 \% \mathrm{~min}$. The crystallinity $(\mathrm{Cr} I)$ was calculated using the peak intensity method, 


$$
\operatorname{CrI}(\%)=\left(I_{200}-I_{a m} / I_{200}\right) \times 100
$$

where $I_{200}$ is the diffraction intensity of $(200)\left(2 \theta=22.5^{\circ}\right)$ and $I_{a m}$ is the diffraction intensity of the amorphous region $\left(2 \theta=18^{\circ}\right)$.

The Fourier transform infrared spectroscopy (FTIR) spectra of the DES-treated samples were recorded on a Fourier transform infrared instrument (Nicolet 10, Thermofisher Scientific, Waltham, MA, USA) in the range from 600 to $4000 \mathrm{~cm}^{-1}$ with a resolution of $4 \mathrm{~cm}^{-1}$. The attenuated total reflection (ATR) method was used for the measurement. A total of 32 scans were taken for each sample.

The morphologies of the samples, with or without DES treatment, were examined by scanning electron microscopy (S-4800, Hitachi, Ltd, Japan) at a $5 \mathrm{kV}$ accelerating voltage.

\section{RESULTS AND DISCUSSION}

\section{Yield of the Solid Residue}

The yield of the solid residue after DES treatments is summarized in Table 1. With increasing molar ratios of $\mathrm{ChCl}$ and HBDs, i.e., the amount of LA and GLY in DES, the yield of solid residue decreased in both sapwood and heartwood, indicating that the watersoluble fraction was increased. The yield in sapwood was higher than in heartwood. In DES with LA, the yield was in the range of 56.4 to $79.7 \%$ and 50.6 to $73.6 \%$ in sapwood and heartwood, respectively, for all molar ratios. These values were lower than the range of 83.0 to $92.4 \%$ and 79.0 to $87.8 \%$ in sapwood and heartwood, respectively, in DES with GLY.

Table 1. Yield of the Solid Residue Obtained after DES Treatments at $100{ }^{\circ} \mathrm{C}$

\begin{tabular}{|c|c|c|c|c|c|}
\hline \multirow{2}{*}{$\begin{array}{l}\text { Molar ratio Sample } \\
\text { of ChCl/HBDs and Time }\end{array}$} & \multicolumn{2}{|c|}{ DES with LA } & \multicolumn{2}{c|}{ DES with GLY } \\
\cline { 2 - 6 } & SW (\%) & HW (\%) & SW (\%) & HW (\%) \\
\hline \multirow{4}{*}{$1: 2$} & $2 \mathrm{~h}$ & 79.7 & 73.6 & 92.4 & 87.8 \\
\cline { 2 - 6 } & $4 \mathrm{~h}$ & 75.6 & 69.7 & 90.1 & 84.8 \\
\cline { 2 - 6 } & $6 \mathrm{~h}$ & 72.6 & 66.8 & 89.7 & 82.7 \\
\cline { 2 - 6 } & $12 \mathrm{~h}$ & 62.7 & 60.0 & 84.5 & 80.5 \\
\hline \multirow{4}{*}{$1: 6$} & $2 \mathrm{~h}$ & 73.8 & 68.5 & 83.5 & 79.6 \\
\cline { 2 - 6 } & $4 \mathrm{~h}$ & 67.7 & 61.8 & 85.2 & 78.1 \\
\cline { 2 - 6 } & $6 \mathrm{~h}$ & 62.7 & 56.8 & 84.4 & 74.9 \\
\cline { 2 - 6 } & $12 \mathrm{~h}$ & 56.4 & 51.8 & 84.6 & 73.0 \\
\cline { 2 - 6 } & $2 \mathrm{~h}$ & 70.7 & 64.9 & 84.5 & 80.1 \\
\cline { 2 - 6 } & $4 \mathrm{~h}$ & 67.6 & 62.3 & 85.9 & 80.6 \\
\cline { 2 - 6 } & $6 \mathrm{~h}$ & 57.5 & 55.7 & 84.8 & 79.8 \\
\hline
\end{tabular}

SW: Sapwood, HW: Heartwood

\section{Chemical Compositions}

Table 2 shows the chemical composition of untreated material, i.e. sapwood and heartwood of red pine. The chemical properties of the sapwood and heartwood of different wood species have been reviewed by several authors. Generally, sapwood contains more cellulose than heartwood (Benouadah et al. 2019). For hemicellulose, only small 
differences have been observed between heartwood and sapwood. Concerning lignin, it has been reported to be present in slightly lesser amounts in heartwood than in sapwood (Li et al. 2019). The total sugar amount of $72.3 \%$ in the sapwood was lower than the $77.5 \%$ in the heartwood. The total lignin content of sapwood was slightly higher than that of heartwood. In this result, cellulose showed the opposite trend from the previous results, but hemicellulose and lignin were similar.

Table 2. Chemical Composition of the Raw Material

\begin{tabular}{|c|c|c|c|c|c|c|c|c|c|}
\hline & \multicolumn{9}{|c|}{ Composition (\%) } \\
\cline { 2 - 11 } & Glu & Xyl & Man & Ara & Gal & $\begin{array}{c}\text { Total } \\
\text { Sugars }\end{array}$ & AIL & ASL & $\begin{array}{c}\text { Total } \\
\text { lignin }\end{array}$ \\
\hline SW & 46.5 & 6.3 & 13.9 & 2.0 & 3.7 & 72.3 & 28.7 & 0.5 & 29.2 \\
\hline HW & 48.9 & 8.7 & 12.4 & 2.5 & 4.9 & 77.5 & 27.1 & 0.5 & 27.6 \\
\hline
\end{tabular}

SW: Sapwood, HW: Heartwood, Glu: Glucose, Xyl: Xylose, Man: Mannose, Gal: Galactose, AlL: Acid insoluble lignin, ASL: Acid soluble lignin

Figures 1 and 2 show the changes in the amounts of cellulose (expressed as glucose), hemicellulose (expressed as the sum of xylose, mannose, arabinose and galactose) and lignin (expressed as the sum of acid insoluble lignin and acid soluble lignin) in the treated product by varying the molar ratio of $\mathrm{ChCl}$ and HBDs (LA and GLY) and treatment time. With increasing molar ratio and treatment time, the amount of cellulose and hemicellulose decreased in both sapwood and heartwood. In particular, the amount of cellulose (Fig. 1. C) was remarkably decreased by increasing the amount of LA in DES, exhibiting the minimum value of $20.9 \%$ in heartwood with a molar ratio of $1: 10$. This value was almost half of the cellulose content of $48.9 \%$ of the untreated material. The amount of hemicellulose (Fig. 1.H) was not substantially different in any samples. Hou et al. (2017b) reported that treatment using ChCl-based DES with oxalic acid can degrade $95.8 \%$ of hemicellulose at $120^{\circ} \mathrm{C}$ for $4 \mathrm{~h}$. Lignin content (Fig. 1. L) was not significantly different among treated products. Even compared to the lignin content $(29.2 \%$ and $27.6 \%$ in sapwood and heartwood, respectively) of the untreated product, the range of 24.5 to $26.5 \%$ in the treated product was slightly changed. In a previous study where the lignocellulosic biomass of rice straw was treated with ChCl-LA DES, the solubility of pure lignin, cellulose and hemicellulose was found to be selective, and lignin dissolved more (Kumar et al. 2016). However, in the present study more cellulose and hemicellulose was removed than lignin, indicating the possible difference in the interaction of DESs with different biomass materials.

The amount of cellulose and hemicellulose (Fig. 2.C, H) by treatment using DES with GLY decreased in both sapwood and heartwood with increasing molar ratio and treatment time. The decrease in cellulose was significant, but the amount of hemicellulose was not significantly different. Compared with the treatment using DES with LA, the reduction rate of hemicellulose by treatment using DES with GLY was less. This could have been caused by the strong acidic properties of LA. The change in the amount of lignin (Fig. 2. L) was not significant. Alvarez-Vasco et al. (2016), suggested that hardly any wood components were removed by $\mathrm{ChCl}$-glycerol treated with different temperature. The results showed that the cellulose and hemicellulose was decreased by increasing the molar ratio and treatment time.

Overall, the heartwood exhibited a greater decreasing rate than the sapwood. The choline chloride based acidic solvents contain a high abundance of nonsymmetric chloride 
ions and carboxylic acid molecules, possessing the features of both ionic liquids and organic solvents. The strong hydrogen bond interactions in cellulose may be weakened because of competing hydrogen bond formation between the chloride ions in DES and the hydroxyl groups in carbohydrates, consequently breaking the intramolecular hydrogen bond network (Liu et al. 2017). In addition to their internal hydrogens bonds, DESs can also form hydrogen bonds with cellulose and dissolve cellulose. Hence, studying the $\mathrm{H}$ bond type and the ability of $\mathrm{H}$ bond formation is crucial for gaining insights into the dissolution of cellulose. In the ChCl-based DESs, one carbonyl oxygen can form two hydrogen bonds, and one hydroxyl oxygen can form one hydrogen bond with cellulose. The $\mathrm{ChCl}$ can accept three $\mathrm{H}^{+}$ions. Hence, two hydrogen bonds can be formed between $\mathrm{ChCl}$ and $\mathrm{LA}$. $\mathrm{ChCl}$ can form a hydrogen bond with cellulose, and LA molecules can form 4 hydrogen bonds with cellulose, giving a total of five bonds with cellulose. GLY can form three hydrogen bonds with $\mathrm{ChCl}$ and three with cellulose. Therefore, the number of hydrogen bonds with cellulose was relatively small for $\mathrm{ChCl} / \mathrm{GLY}$ compared to $\mathrm{ChCl} / \mathrm{LA}$, and hence the dissolution of cellulose is more in LA than GLY (Zhang et al. 2020). Furthermore, increase in the reaction time and HBD ratio also resulted in the increased dissolution, in accordance with the literature reports. Chen et al. (2019) reported that under the same temperature, the solubility of poplar wood meal in the DES showed an upward trend with the increase of the dissolving time. van Osch et al. (2017) observed that the dissolvability of the cellulose was increased with increasing HBD ratio. Therefore, the heartwood with a high cellulose and hemicellulose content was decreased more than sapwood, and the yield of the heartwood (shown in Table 1) was lower than that of the sapwood.
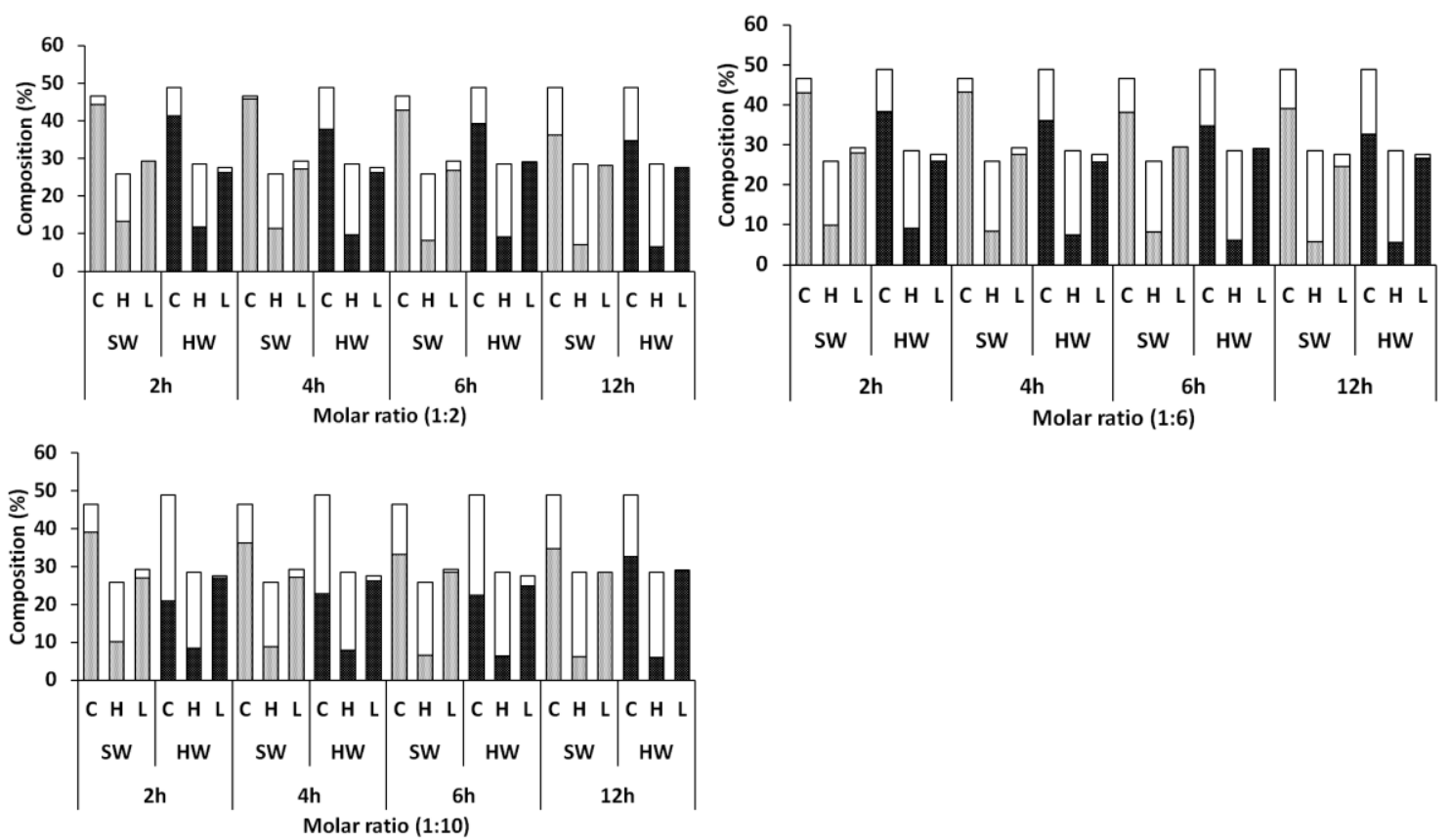

Fig. 1. Chemical compositions(C: Cellulose, H: Hemicellulose, L: Lignin) of the soluble fraction( $\square$ ) and solid residue ( $\square$ :Sapwood (SW), ${ }^{0}$ : Heartwood (HW) after DES with LA with different molar ratios and treatment time at $100^{\circ} \mathrm{C}$ 

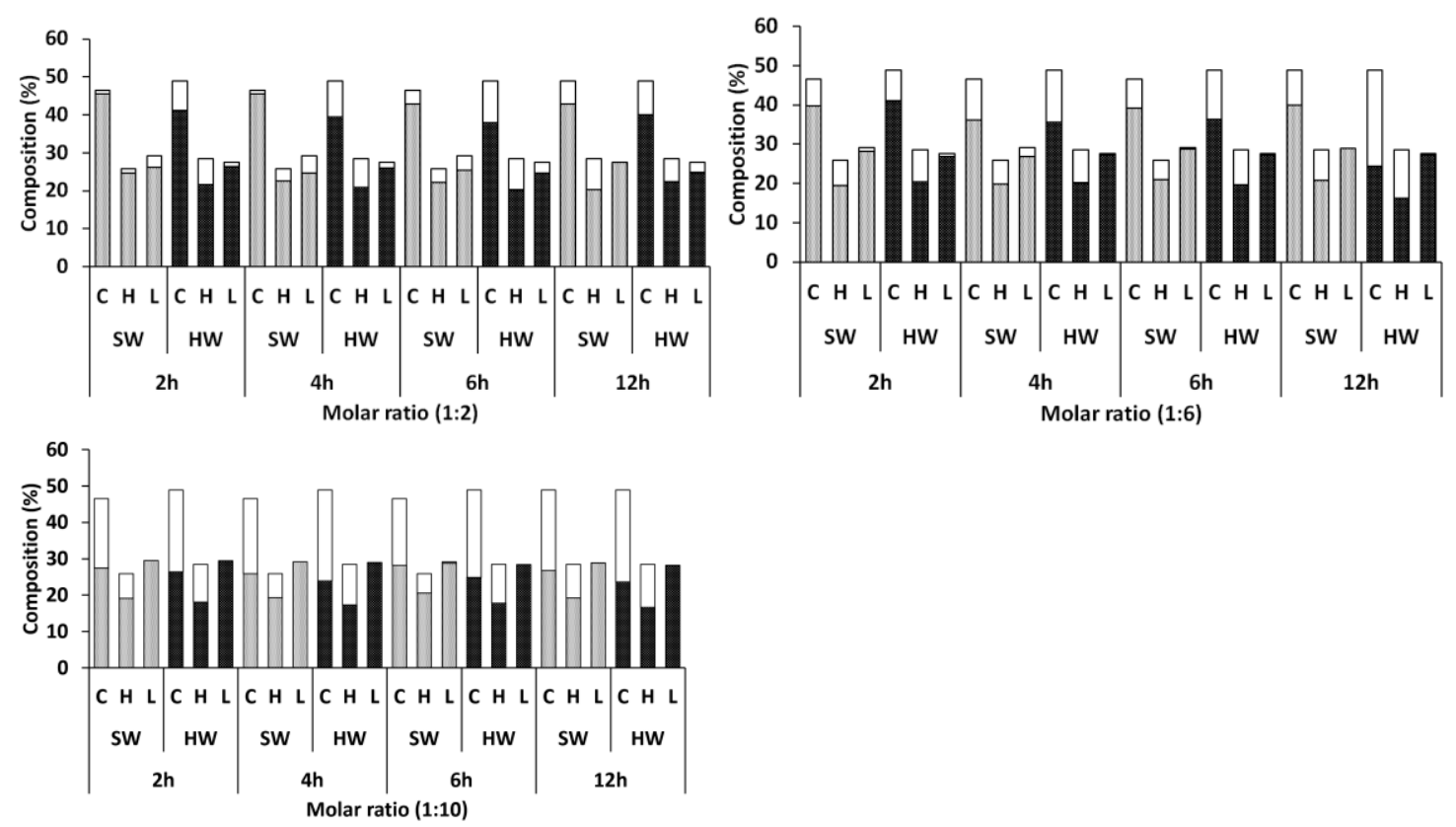

Fig. 2. Chemical compositions(C: Cellulose, H: Hemicellulose, L: Lignin) of the soluble fraction( $\square$ ) and solid residue ( $\square$ :Sapwood (SW), Heartwood (HW) after DES with GLY with different molar ratios and treatment time at $100^{\circ} \mathrm{C}$

\section{X-ray Diffraction (XRD) of DES-treated and Untreated Samples}

Figure 3 shows the XRD patterns of the DES-treated and untreated sapwood. All samples exhibited the typical diffraction pattern of the cellulose I polymorph, indicating that the treatment using DES with LA and GLY did not affect the cellulose structure regardless of the molar ratio and treatment time. The crystallinity values in all samples are summarized in Table 3.

The crystallinity of the untreated material was $46.2 \%$ and $53.8 \%$ in sapwood and heartwood, respectively. The crystallinity values of the treated products using DES with LA were higher than those using DES with GLY under all treatment conditions. This may have been caused by the lower yield of the solid residue in the treated product using DES with LA.

Procentese et al. (2015) reported that the increase in the degree of cellulose crystallinity after treatment using ChCl-based DES with GLY, urea, and imidazole was mainly caused by the removal of the amorphous hemicellulose and lignin. However, there was little difference with various molar ratios and treatment times in all samples. Overall, the crystallinity of both sapwood and heartwood treated with both DES with LA and GLY was somewhat higher than that of the untreated material. Relatively, the wood samples (both sapwood and heartwood) treated by DES with LA were more crystalline than that of DES with GLY. Moreover, with both types of DESs heartwood appeared less crystalline than sapwood.

Satlewal et al. (2018) reported that the crystallinity of biomass increased after treatment of DESs, usually due to the removal of lignin as well as amorphous hemicellulose. Hence, it can be expected that, compared to the DES with LA, DES with GLY has the less efficiency of removing amorphous hemicellulose and also, the less crystallinity of the heartwood is thought to be due to this difference. 


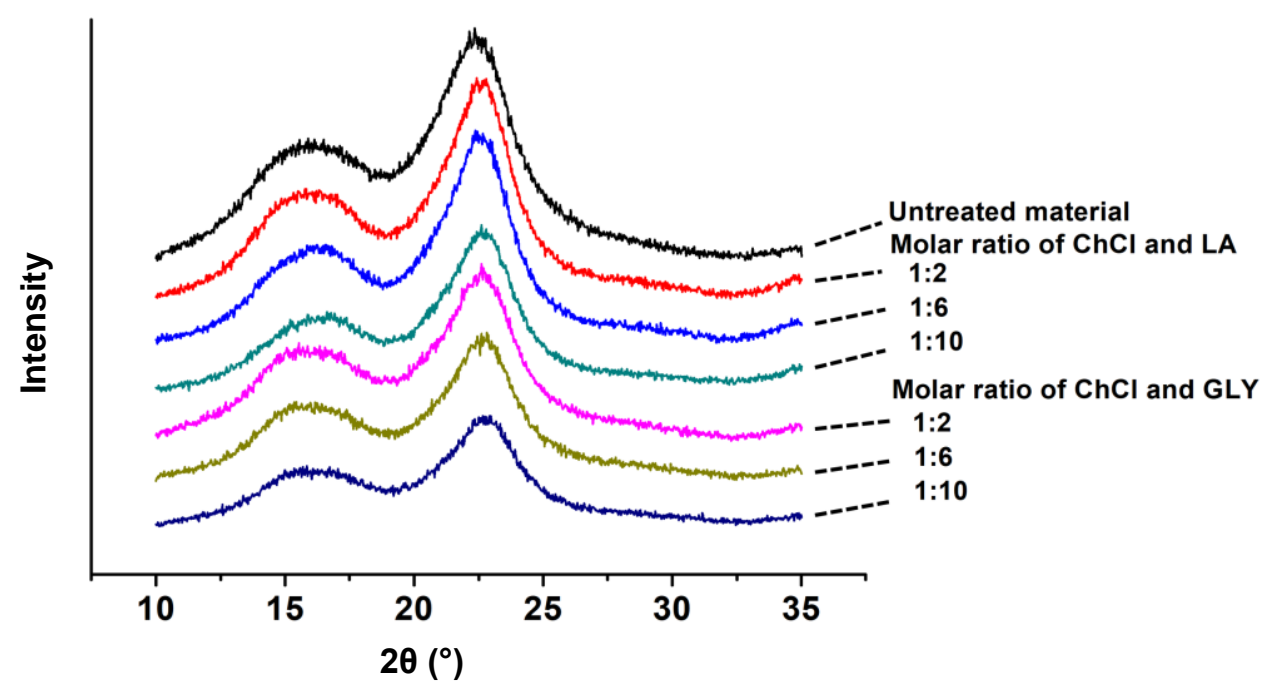

Fig. 3. XRD patterns of the untreated material and DES-treated products with different molar ratios of $\mathrm{ChCl}$ and $\mathrm{HBDs}$ for $12 \mathrm{~h}$ at $100^{\circ} \mathrm{C}$ using red pine sapwood

Table 3. Summary of the Crystallinity of DES-treated Products at $100^{\circ} \mathrm{C}$

\begin{tabular}{|c|c|c|c|c|c|}
\hline \multirow{2}{*}{$\begin{array}{l}\text { Molar ratio } \\
\text { of ChCl/HBDs and Time }\end{array}$} & \multicolumn{2}{|c|}{ DES with LA } & \multicolumn{2}{c|}{ DES with GLY } \\
\cline { 2 - 6 } & SW (\%) & HW (\%) & SW (\%) & HW (\%) \\
\hline \multicolumn{2}{|c|}{ Untreated material } & 46.2 & 48.7 & - & - \\
\hline \multirow{4}{*}{$1: 2$} & $2 \mathrm{~h}$ & 57.3 & 54.1 & 52.5 & 51.6 \\
\cline { 2 - 6 } & $4 \mathrm{~h}$ & 58.2 & 55.7 & 53.0 & 52.5 \\
\cline { 2 - 6 } & $6 \mathrm{~h}$ & 57.7 & 57.7 & 53.1 & 52.9 \\
\cline { 2 - 6 } & $12 \mathrm{~h}$ & 59.7 & 58.5 & 53.3 & 53.1 \\
\hline \multirow{4}{*}{$1: 6$} & $2 \mathrm{~h}$ & 57.9 & 56.6 & 51.4 & 52.2 \\
\cline { 2 - 6 } & $4 \mathrm{~h}$ & 57.4 & 56.7 & 50.0 & 51.3 \\
\cline { 2 - 6 } & $6 \mathrm{~h}$ & 58.3 & 56.8 & 52.5 & 52.6 \\
\hline \multirow{4}{*}{$1: 10$} & $12 \mathrm{~h}$ & 60.9 & 60.0 & 51.0 & 51.6 \\
\cline { 2 - 6 } & $2 \mathrm{~h}$ & 56.1 & 54.5 & 51.4 & 52.4 \\
\cline { 2 - 6 } & $4 \mathrm{~h}$ & 56.5 & 54.8 & 50.5 & 50.0 \\
\cline { 2 - 6 } & $6 \mathrm{~h}$ & 57.7 & 57.3 & 50.6 & 51.0 \\
\hline
\end{tabular}

SW: Sapwood, HW: Heartwood

\section{Functional Group Analysis of the DES-treated and Untreated Samples}

The FTIR spectra of the untreated and DES-treated sapwood with different molar ratios of $\mathrm{ChCl}$ and LA or GLY are shown in Fig. 4. There was no significant change in any of the spectra because the DES-treated products contained all components of cellulose, hemicellulose, and lignin.

The broad absorbance region in the range of 3300 to $3500 \mathrm{~cm}^{-1}$ corresponds to the stretching of hydroxyl groups of cellulose, hemicellulose, and lignin. The absorbance in the range of 2800 to $2900 \mathrm{~cm}^{-1}$ is caused by $\mathrm{CH}$ stretching in the crystalline region of cellulose. The individual band in the region 1800 to $800 \mathrm{~cm}^{-1}$ is related to the absorbed O$\mathrm{H}$ vibration, $\mathrm{CH}$ deformation, $\mathrm{C}-\mathrm{O}$ stretch lignin, and carbohydrates (Gupta et al., 2015). In particular, the intensity of the peak at $1104 \mathrm{~cm}^{-1}$ caused by the vibration of cellulose 
alcohol was very small in the untreated sample, whereas it increased in the DES-treated products. This result indicated that lignin removal by DES treatment exposed cellulose on the surface of the DES-treated products.

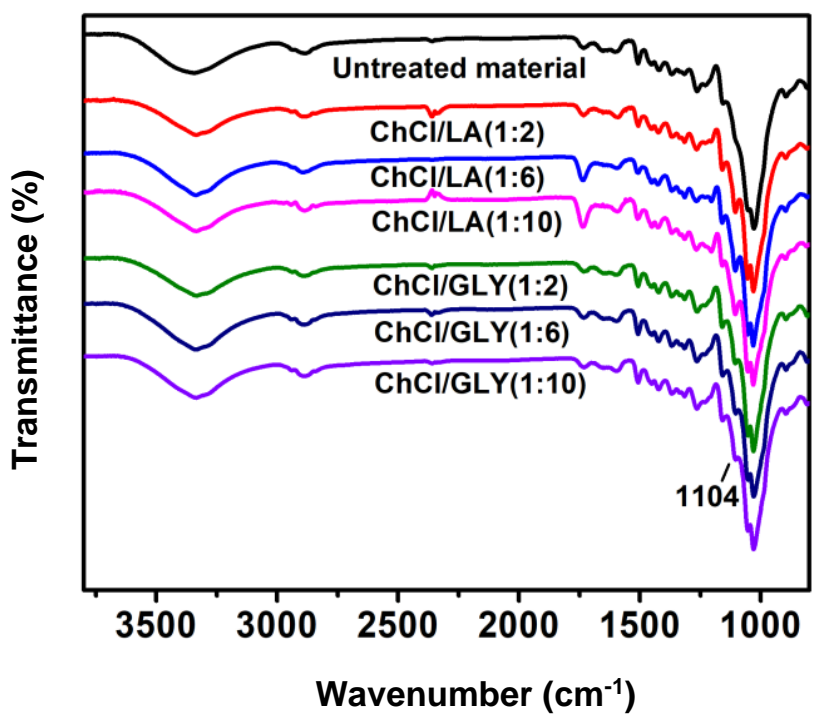

Fig. 4. FT-IR spectra of the untreated material and DES-treated products with different molar ratios of $\mathrm{ChCl}$ and $\mathrm{HBDs}$ for $12 \mathrm{~h}$ at $100^{\circ} \mathrm{C}$ using red pine sapwood

\section{SEM Observation of the DES-treated and Untreated Samples}

Figure 5 shows the SEM images of red pine sapwood samples, including untreated and treated specimens with DES at different HBD ratios for $12 \mathrm{~h}$ at $100{ }^{\circ} \mathrm{C}$. The untreated material (Fig. 5a) displays a rigid and rough surface morphology. By contrast, the surfaces of the DES treated products (Fig. $5 \mathrm{~b}-\mathrm{g}$ ) were broken into separate fibers or fiber bundles and became smoother in comparison to the untreated material. These results suggest that DES treatment significantly removed the chemical components of red pine to different extents. However, there seems to have been little difference according to the molar ratio.
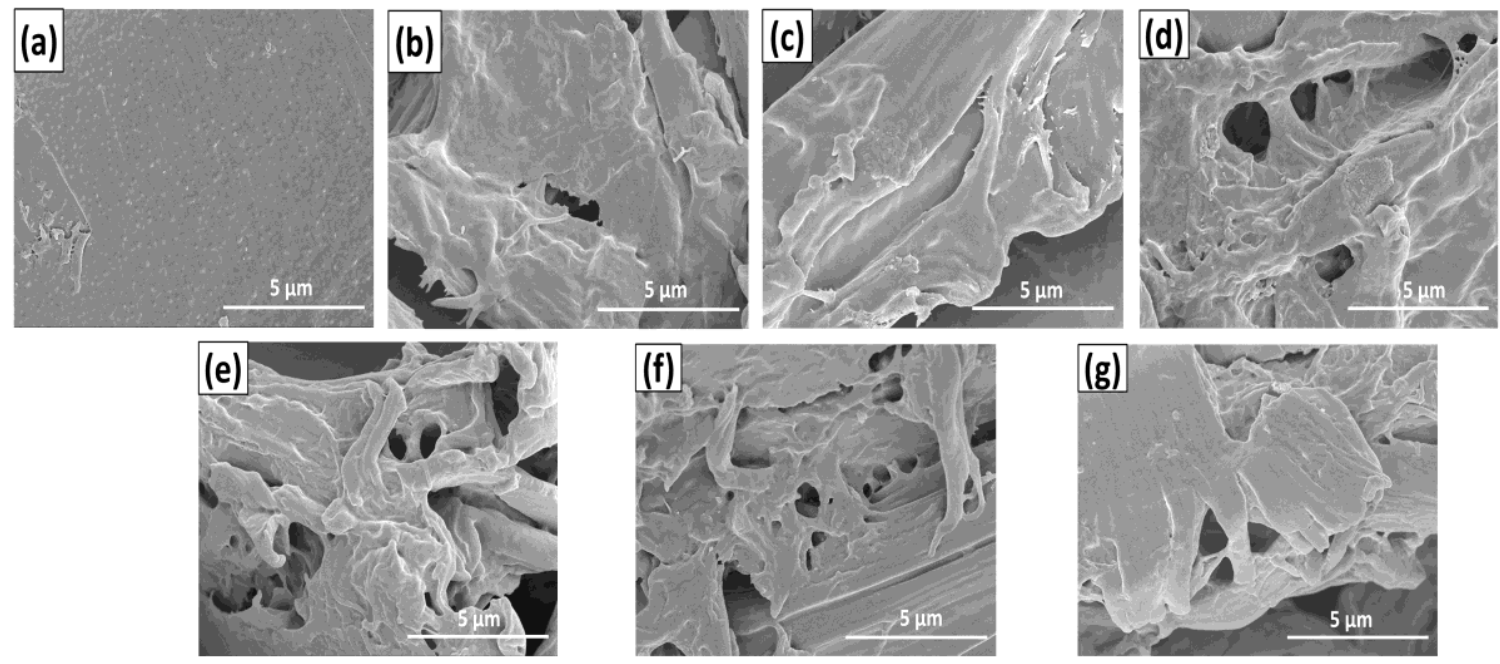

Fig. 5. SEM image illustrating the morphology of the untreated material (a) and DES-treated products (ChCl/LA 1:2(b), ChCl/LA 1:6(c), ChCl/LA 1:10(d), ChCl/GLY 1:2(e), ChCl/GLY 1:6 (f) and $\mathrm{ChCl} / \mathrm{GLY} 1: 10(\mathrm{~g})$ ) with different molar ratios of $\mathrm{ChCl}$ and $\mathrm{HBDs}$ for $12 \mathrm{~h}$ at $100{ }^{\circ} \mathrm{C}$ using red pine sapwood. 


\section{CONCLUSIONS}

The effects of various molar ratios and treatment time with different $\mathrm{pH}$ DES buffer systems made from a mixture of choline chloride $(\mathrm{ChCl})$ and two hydrogen bond donors (HBDs) lactic acid (LA) and glycerin (GLY) on the chemical composition of sapwood and heartwood of red pine was studied.

1. Deep eutectic solvent (DES) treatment significantly decreased the yield of solid residue with an increase in the HBD (LA, GLY) molar ratio and treatment time.

2. Chemical composition analysis of residues revealed that the content of total sugars was gradually decreased as the treatment time and HBD molar ratios were increased, and were higher in sapwood than in heartwood.

3. $\mathrm{ChCl} / \mathrm{LA}$ solvent with a low $\mathrm{pH}$ value dissolved hemicellulose a lot regardless of the treatment time and molar ratio, which resulted in high crystallinity. In addition, heartwood with high cellulose content was more soluble than sapwood, and these results were greatly affected by treatment time and molar ratio.

4. The $\mathrm{pH}$ value of DES in the process of DES treatment based on choline chloride at $100{ }^{\circ} \mathrm{C}$ was a key factor affecting the cellulose and hemicellulose solubility of biomass. Overall, the low $\mathrm{pH} \mathrm{DES}$, i.e. $\mathrm{ChCl} / \mathrm{LA}$, is promising with the mole ratio of 1:2 and treatment time of $6 \mathrm{~h}$ for the pretreatment of red pine.

\section{ACKNOWLEDGMENTS}

This research was supported by Basic Science Research Program through the National Research Foundation of Korea (NRF) funded by the Ministry of Education (No. 2018R1A6A1A03025582; No. 2018R1D1A1B07050930) and the support of the R\&D Program for Forest Science Technology (Project No. 2019151A00-2023-0301) provided by Korea Forest Service (Korea Forestry Promotion Institute).

\section{REFERENCES CITED}

Agbor, V. B., Cicek, N., Sparling, R., Berlin, A., and Levin, D. B. (2011). "Biomass pretreatment: Fundamentals toward application," Biotechnology Advances 29(6), 675685. DOI: 10.1016/j.biotechadv.2011.05.005

Ahorsu, R., Medina, F., and Constantí, M. (2018). "Significance and challenges of biomass as a suitable feedstock for bioenergy and biochemical production: A review," Energies 11(12), Article 3366. DOI: 10.3390/en11123366

Alvarez-Vasco, C., Ma, R., Quintero, M., Guo, M., Geleynse, S., Ramasamy, K. K., Wolcott, M., and Zhang, X. (2016). "Unique low-molecular-weight lignin with high purity extracted from wood by deep eutectic solvents (DES): A source of lignin for valorization," Green Chemistry 18(19), 5133-5141. DOI: 10.1039/c6gc01007e

Benouadah, N., Aliouche, D., Pranovich, A., and Willför, S. (2019). "Chemical characterization of Pinus halepensis sapwood and heartwood," Wood Material Science \& Engineering, 14(3), 157-164. DOI: 10.1080/17480272.2018.1448436 
Chen, Y., Zhang, L., Yu, J., Lu, Y., Jiang, B., Fan, Y., and Wang, Z. (2019). "High-purity lignin isolated from poplar wood meal through dissolving treatment with deep eutectic solvents," Royal Society Open Science 6(1), 181757. DOI: 10.1098/rsos. 181757

Capolupo, L., and Faraco, V. (2016). "Green methods of lignocellulose pretreatment for biorefinery development," Applied Microbiology and Biotechnology 100(22), 94519467. DOI: 10.1007/s00253-016-7884-y

Dai, Y., Witkamp, G. J., Verpoorte, R., and Choi, Y. H. (2013). "Natural deep eutectic solvents as a new extraction media for phenolic metabolites in Carthamus tinctorius L," Analytical Chemistry 85(13), 6272-6278. DOI: 10.1021/ac400432p

Espinoza-Acosta, J. L., Torres-Chávez, P. I., Carvajal-Millán, E., Ramírez-Wong, B., Bello-Pérez, L. A., and Montaño-Leyva, B. (2014). "Ionic liquids and organic solvents for recovering lignin from lignocellulosic biomass," BioResources 9(2), 3660-3687. DOI: 10.15376/biores.9.2.3660-3687

George, A., Brandt, A., Tran, K., Zahari, S. M. S. N. S., Klein-Marcuschamer, D., Sun, N., Sathitsuksanoh, N., Shi, J., Stavila, V., Parthasarathi, R., Singh, S., Holmes, B. M., Welton, T., Simmons, B. A., and Hallett, J. P. (2015). "Design of low-cost ionic liquids for lignocellulosic biomass pretreatment," Green Chemistry 17(3), 1728-1734. DOI: 10.1039/C4GC01208A

Gupta, B. S., Jelle, B. P., and Gao, T. (2015). "Wood facade materials ageing analysis by FTIR spectroscopy," Proceedings of the Institution of Civil Engineers - Construction Materials 168(5), 219-231. DOI: 10.1680/coma.13.00021

Han, S. Y., Park, C. W., and Lee, S. H. (2017). "Preparation of lignocellulose nanofiber by mechanical defibrillation after pretreating using cosolvent of ionic liquid and DMF," Journal of the Korean Wood Science and Technology 43(3), 268-277. DOI: 10.5658/WOOD.2017.45.3.268

Han, S. Y., Park, C. W., Park, J. B., Ha, S. J., Kim, N. H., and Lee, S. H. (2020). "Ethanol fermentation of the enzymatic hydrolysates from the products pretreated using [EMIM]Ac and its co-solvents with DMF," Journal of Forest and Environment Science 36 (1), 62-66. DOI: 10.7747/JFES.2020.36.1.62

Hiltunen, J., Kuutti, L., Rovio, S., Puhakka, E., Virtanen, T., Ohra-Aho, T., and Vuoti, S. (2016). "Using a low melting solvent mixture to extract value from wood biomass," Scientific Reports 6(1), 32420. DOI: 10.1038/srep32420

Ho, M. C., Ong, V. Z., and Wu, T. Y. (2019). "Potential use of alkaline hydrogen peroxide in lignocellulosic biomass pretreatment and valorization - A review," Renewable and Sustainable Energy Reviews 112, 75-86. DOI: 10.1016/j.rser. 2019.04.082

Hou, Q., Ju, M., Li, W., Liu, L., Chen, Y., and Yang, Q. (2017a). "Pretreatment of lignocellulosic biomass with ionic liquids and ionic liquid-based solvent systems," Molecules 22(3), 490. DOI: 10.3390/molecules22030490

Hou, X. D., Feng, G. J., Ye, M., Huang, C. M., and Zhang, Y. (2017b). “Significantly enhanced enzymatic hydrolysis of rice straw via a high-performance two-stage deep eutectic solvents synergistic pretreatment," Bioresource Technology 238, 139-146. DOI: 10.1016/j.biortech. 2017.04.027

Isikgor, F. H., and Becer, C. R. (2015). "Lignocellulosic biomass: A sustainable platform for the production of bio-based chemicals and polymers," Polymer Chemistry 6(25), 4497-4559. DOI: 10.1039/C5PY00263J

Kadhom, M. A., Abdullah, G. H., and Al-Bayati, N. (2017). "Studying two series of 
ternary deep eutectic solvents (choline chloride-urea-glycerol) and (choline chloridemalic acid-glycerol), synthesis and characterizations," Arabian Journal for Science and Engineering 42(4), 1579-1589. DOI: 10.1007/s13369-017-2431-4

Kucharska, K., Rybarczyk, P., Hołowacz, I., Łukajtis, R., Glinka, M., and Kamiński, M. (2018). "Pretreatment of lignocellulosic materials as substrates for fermentation processes," Molecules 23(11), 2937. DOI: 10.3390/molecules23112937

Kumar, A. K., Parikh, B. S., and Pravakar, M. (2016). "Natural deep eutectic solvent mediated pretreatment of rice straw: Bioanalytical characterization of lignin extract and enzymatic hydrolysis of pretreated biomass residue," Environmental Science and Pollution Research 23(10), 9265-9275. DOI: 10.1007/s11356-015-4780-4

Lee, S. H., Kim, H. J., and Kim, J. C. (2019). "Nanocellulose applications for drug delivery: A review," Journal of Forest and Environmental Science 35(3), 141-149. DOI: 10.7747/JFES.2019.35.3.141

Li, Y. F., Deng, X. W., Zhang, Y. F., Huang, Y. Q., Wang, C. Y., Xiang, W. H., Xiao, F. M., and Wei, X. C. (2019). "Chemical characteristics of heartwood and sapwood of red heart Chinese fir (Cunninghamia lanceolata)," Forest Products Journal 69(2), 103-109. DOI: 10.13073/FPJ-D-18-00042

Liu, Y., Guo, B., Xia, Q., Meng, J., Chen, W., Liu, S., Wang, Q., Liu, Y., Li, J. and Yu, H. (2017). "Efficient cleavage of strong hydrogen bonds in cotton by deep eutectic solvents and facile fabrication of cellulose nanocrystals in high yields," ACS Sustainable Chemistry \& Engineering 5(9), 7623-7631. DOI: 10.1021/ acssuschemeng.7b00954

Loow, Y.-L., Wu, T. Y., Yang, G. H., Ang, L. Y., New, E. K., Siow, L. F., Jahim, J. M., Mohammad, A. W., and Teoh, W. H. (2018). "Deep eutectic solvent and inorganic salt pretreatment of lignocellulosic biomass for improving xylose recovery," Bioresource Technology 249, 818-825. DOI: 10.1016/j.biortech.2017.07.165

Malaeke, H., Housaindokht, M. R., Monhemi, H., and Izadyar, M. (2018). "Deep eutectic solvent as an efficient molecular liquid for lignin solubilization and wood delignification," Journal of Molecular Liquids 263, 193-199. DOI: 10.1016/j.molliq.2018.05.001

Merza, F., Fawzy, A., AlNashef, I., Al-Zuhair, S., and Taher, H. (2018). "Effectiveness of using deep eutectic solvents as an alternative to conventional solvents in enzymatic biodiesel production from waste oils," Energy Reports 4, 77-83. DOI: 10.1016/j.egyr.2018.01.005

Ong, V. Z., Wu, T. Y., Lee, C. B. T. L., Cheong, N. W. R., and Shak, K. P. Y. (2019). "Sequential ultrasonication and deep eutectic solvent pretreatment to remove lignin and recover xylose from oil palm fronds," Ultrasonics Sonochemistry 58, 104598. DOI: 10.1016/j.ultsonch.2019.05.015

Procentese, A., Johnson, E., Orr, V., Garruto Campanile, A., Wood, J. A., Marzocchella, A., and Rehmann, L. (2015). "Deep eutectic solvent pretreatment and subsequent saccharification of corncob," Bioresource Technology 192, 31-36. DOI: 10.1016/j.biortech.2015.05.053

Sakti, A. S., Saputri, F. C., and Mun'im, A. (2019). "Optimization of choline chlorideglycerol based natural deep eutectic solvent for extraction bioactive substances from Cinnamomum burmannii barks and Caesalpinia sappan heartwoods," Heliyon 5(12), e02915. DOI: 10.1016/j.heliyon.2019.e02915 
Sathitsuksanoh, N., George, A., and Zhang, Y. H. P. (2012). "New lignocellulose pretreatments using cellulose solvents: A review," Journal of Chemical Technology \& Biotechnology 88(2), 169-180. DOI: 10.1002/jctb.3959

Satlewal, A., Agrawal, R., Bhagia, S., Sangoro, J., and Ragauskas, A. J. (2018). "Natural deep eutectic solvents for lignocellulosic biomass pretreatment: Recent developments, challenges and novel opportunities," Biotechnology Advances 36. 2032-2050. DOI: 10.1016/j.biotechadv.2018.08.009

Shamsuri, A. A., and Abdullah, D. K. (2010). "Ionic liquids: Preparations and limitations," Makara Sains 14(2), 101-106. DOI: 10.7454/mss.v14i2.677

Sirviö, J. A., Visanko, M., and Liimatainen, H. (2015). "Deep eutectic solvent system based on choline chloride-urea as a pre-treatment for nanofibrillation of wood cellulose," Green Chemistry 17(6), 3401-3406. DOI: 10.1039/c5gc00398a

Sirviö, J. A., Visanko, M., and Liimatainen, H. (2016). “Acidic deep eutectic solvents as hydrolytic media for cellulose nanocrystal production," Biomacromolecules 17(9), 3025-3032. DOI: 10.1021/acs.biomac.6b00910

Skulcova, A., Russ, A., Jablonsky, M., and Sima, J. (2018). The pH behavior of seventeen deep eutectic solvents," BioResources 13, 5042-5051. DOI: 10.15376/biores.13.5042-5051

Sluiter, A., Hames, B., Ruiz, R., Scarlata, C., Sluiter, J., Templeton, D., and Crocker, D. (2008). Determination of Structural Carbohydrates and Lignin in Biomass (NREL/TP-510-42618), National Renewable Energy Laboratory, Golden, CO, USA.

Smink, D., Juan, A., Schuur, B., and Kersten, S. R. A. (2019). "Understanding the role of choline chloride in deep eutectic solvents used for biomass delignification," Industrial \& Engineering Chemistry Research 58, 16348-16357. DOI: 10.1021/acs.iecr.9b03588

Sun, N., Rahman, M., Qin, Y., Maxim, M. L., Rodríguez, H., and Rogers, R. D. (2009). "Complete dissolution and partial delignification of wood in the ionic liquid 1-ethyl-3-methylimidazolium acetate," Green Chemistry 11(5), 646-655. DOI: 10.1039/B822702K

Van Osch, D. J. G. P., Kollau, L. J. B. M., van den Bruinhorst, A., Asikainen, S., Rocha, M. A. A., and Kroon, M. C. (2017). "Ionic liquids and deep eutectic solvents for lignocellulosic biomass fractionation," Physical Chemistry Chemical Physics 19(4), 2636-2665. DOI: 10.1039/c6cp07499e

Yadav, A., Trivedi, S., Rai, R., and Pandey, S. (2014). "Densities and dynamic viscosities of (choline chloride+glycerol) deep eutectic solvent and its aqueous mixtures in the temperature range (283.15-363.15) K," Fluid Phase Equilibria 367, 135-142. DOI: 10.1016/j.fluid.2014.01.028

Yu, W., Wang, C., Yi, Y., Zhou, W., Wang, H., Yang, Y., and Tan, Z. (2019). "Choline chloride-based deep eutectic solvent systems as a pretreatment for nanofibrillation of ramie fibers," Cellulose 26, 3069-3082. DOI: 10.1007/s10570-019-02290-7

Zhang, H., Lang, J., Lan, P., Yang, H., Lu, J., and Wang, Z. (2020). "Study on the dissolution mechanism of cellulose by ChCl-based deep eutectic solvents," Materials 13(2), 278. DOI: 10.3390/ma13020278

Zhang, K., Pei, Z., and Wang, D. (2016). "Organic solvent pretreatment of lignocellulosic biomass for biofuels and biochemicals: A review," Bioresource Technology 199, 2133. DOI: 10.1016/j.biortech.2015.08.102 
Zhao, H. (2003). "Review: Current studies on some physical properties of ionic liquids," Physics and Chemistry of Liquids 41(6), 545-557. DOI: 10.1080/00319103100011 7319

Article submitted: March 19, 2020; Peer review completed: June 4, 2020; Revised version received and accepted: June 28, 2020; Published: July 6, 2020.

DOI: $10.15376 /$ biores. 15.3.6457-6470 